\title{
Clinical Data Driven Decision Support in Healthcare Informatics
}

\author{
Milind Godbole ${ }^{1}$ and Dr. Anuja Agarwal ${ }^{2}$ \\ ${ }^{1}$ Research PhD Student, Narsee Monjee Institute of Management Studies, Mumbai, India. \\ ${ }^{2}$ Associate Dean, Technology Management, Narsee Monjee Institute of Management Studies, Mumbai, India.
}

\begin{abstract}
Healthcare pioneers are commonly aware of big data to feature trends, patterns of health, as well as potential outcomes for a group of individuals or large population, however for transforming and translating the medical data to make a beneficial interpretation and decisions for aiding in healthcare and medical decision-making, there is a large there is an enormous prerequisite of health informatics and data analytics approaches such as decision support systems. Also, the healthcare sector has been generally lagging in the implementation of Decision Analysis. Therefore, the current review is aimed at identifying the current trends, applications and processes of healthcare data analytics and health informatics with decision support systems for the assistance of healthcare experts, researchers, and analysts to acquire an indepth understanding in their clinical applications. In conclusion, it can be mentioned that the improved decisionmaking algorithms in healthcare informatics can assist in improved approaches to deal with the detection of security problems with medications, equipment and robust techniques for comparative analysis of symptomatic, prevention and treatment alternatives.
\end{abstract}

Keywords: Healthcare, Healthcare Informatics, Data Analytics, Decision Support System, Decision-Analysis

\section{INTRODUCTION}

Currently, on a global scale, the healthcare frameworks are constantly advancing towards extensive usage as well as dependability on information technology, electronic health records, and automation. The healthcare sector has greatly witnessed a paradigm shift due to the quick innovation in technologies such as wearable systems, portable networks (Olla, 2005), information communication technology (Godoe, 2000), nanotechnology, biomonitoring (Budinger, 2003), pervasive computing (Akyildiz and Rudin, 2001), and approaches of drug delivery (Grayson, et al., 2004). Therefore, the uprising of information technology into the healthcare practice is causing a transformation in research outlook that is merging the boundaries amongst patient care, public health, as well as preventive health (Hatcher and Heetebry, 2004).

Also, on the economic front of diverse nations, the healthcare sector is exponentially booming with advanced development and information (Yang et al. 2015). With its development, come difficulties including increasing costs, wasteful aspects, poor quality, and expanding multifaceted nature (Cortada et al.
2012). In the United States alone, the costs of healthcare rose by $123 \%$ nearly from $\$ 2.6$ trillion to $\$ 3.2$ trillion, from the period ranging from 2010 and 2015 (National Health Expenditure Projections, 2018). Similarly, the non-useful or non-beneficial tasks including healthcare fraud, improper utilization of antibiotics, and readmissions of patients established $21-47 \%$ of the enormous costs in the healthcare sector (Hackbarth and Berwick, 2012).

Furthermore, the institutions in the healthcare sector are exceedingly adopting information technology in the framework of their management (Ganslandt and Prokosch, 2009). This healthcare framework assists in the assembly of the enormous volume of information. Health information management and Health informatics have played an indispensable role in the validation of the assemblage of healthcare knowledge through precise examination and assessment based on sound research strategies (Brodnik, Layman, and Watzlaf, 2012). The term Health informatics can be characterized as a broad term that involves various disciplines that include the utilization of information science and computer to manage and process most of the healthcare information and information management (Brodnik et al., 2012).

Hence, in health informatics and management, analytics offers multiple tools, techniques and approaches to extract and process the relevant information from the complicated array of ample information (Cortada et al. 2012). The extracted information is then translated into data that can help the process of decision-making in healthcare. As an instance, according to certain reports, in the United States, the use of data mining can spare $\$ 450$ billion every year from the system of healthcare (Herland, Khoshgoftaar, and Wald 2014).

Further, the Ministry of Health has expressed their consideration of the potential of the automated frameworks in healthcare to execute and guarantee the proper utilization of an intervention. The use of systems in healthcare in the context of the clinical intervention can be viewed as a part of a practical insight that requires knowledge of the infrastructure of the framework, organization, obstructions, and aptitudes (Hatcher and Heetebry, 2004). Moreover, bringing a proper model into the qualitative decision analysis offers structure to these contemplations and infers that interventions that are simple to apply and exhibit inherently lower risks in the case of improper use are more crucial. As a result, in biomedicine and healthcare, the big data has been established as a discipline of an extensive consideration. It is therefore important to understand the motivation behind the underlying factors regarding why this huge information is playing a key role in the network of 
healthcare informatics. The ability to handle enormous information is facilitating the conduction of unparalleled research in this area to actualize new models of healthcare delivery and management (Bellazi, 2014).

In addition, diverse clinical applications ranging from the study of disease transmission to patient care can highly profit by the employment of the voluminous big data that are easily accessible such as individual pre- and intraoperative patient monitoring to postoperative patient care. However, development and assembly of the healthcare systems that are empowered to operate big data in healthcare informatics bear certain repercussions regarding reproducibility of research studies and management of protection and information access and other similar issues. An intriguing result of the voluminous data situation is the development of novel techniques, and tools, software's and online management systems for example, distributed computing, and AI algorithms, that will not only add to research in context with big data, however, might be highly profitable in many healthcare informatics applications such as for decision-analysis by decision support systems.

The healthcare sector has been generally lagging in the implementation of Decision Analysis. In any case, as more healthcare experts and researchers have turned out to be aware of the systems, there has been a substantial hike in the application of Decision support systems in healthcare decisionanalysis (Diaby et al. 2013; Marsh et al. 2014). As observed, most information technology systems in the healthcare sector continue to depend on data warehouse structures, due to which without the incorporation and introduction of correct architecture and infrastructure of IT, analytic tools, work flows, approaches of visualization, and GUI, the in-depth insights offered by approaches of big-data in health informatics and healthcare analytics, are probably going to be constrained. Further, to create the successful value of big-data in healthcare decision analysis and informatics, the healthcare sector may need novel techniques and modifications in current policies to equalize the potential advantages of approaches of decisionanalysis in healthcare analytics as well as the security and confidentiality of patients' data. Other implications of utilizing the large information are that many current practices and approaches identified with information use, sharing, access, security, should be updated.

Typically, for the clinicians assisting patients for care, there are several vulnerabilities that arise quite often and exceed what is known. They regularly have inadequate information to decide in explicit instances which systems to grasp and which to keep away from on the basis of a decision that is genuinely informed by precise data associated with perceived risks and advantages (Barnett et al. 2011). Although, during the time when proof is present regarding a specific decision, it frequently isn't relevant to the individual in need (Krumholz, 2014). Moreover, the information created in regular medicinal practice is to a great extent squandered. Therefore, to inform and make decisions in an improved manner in the healthcare sector, there is a critical need for customized predictions about treatment and prognosis based on decisions as well as for profound understanding of the unpredictable factors and their key interactions that impact health at the patient level, the health framework. Improved decision-making algorithms in healthcare informatics can assist in improved approaches to deal with the detection of security problems with medications, equipment and robust techniques for comparative analysis of symptomatic, prevention and treatment alternatives.

\section{AIMS AND OBJECTIVES}

The current review is aimed at identifying and providing an indepth understanding of the current techniques and applications of decision support system in healthcare informatics and analytics. Therefore, the review aims to address the following objectives:

1. To comprehend the use of a Decision Support System in healthcare informatics and management.

2. To identify determinants and factors of decision-analysis framework in current approaches in healthcare informatics.

3. To develop a conceptual model and suggest strategies based on the identified variables in healthcare decision systems.

\section{LITERATURE REVIEW}

\subsection{Healthcare Informatics in the healthcare system}

Health informatics can be characterized as the control that coordinates biomedical sciences, computers and health care approach, management and organization (Peel 1994). Health Informatics is typically heterogeneous in nature similar to medicinal sciences due to which the epistemological, as well as methodological problems associated with the medicine and healthcare practices, may not be avoided (Marceglia et al. 2016).

Georgiou (2002) demonstrated that the model of health informatics comprises of three vital components that include information, data and knowledge. These components are arranged in an order that consists of data at the base of the model giving the premise to build up information and driving thusly to the robust generation of knowledge. The research also observed the close association of the informatics model converging nearly with the standards, objectives and errands of Evidence-based prescription (EBM), especially as they identify with an extensive search, assessment, investigation and employing the research data. Peel (1994), mentioned that the significance of informatics in the healthcare sector is beyond an outcome of quick improvements and innovations in Information Technology. It is exceptionally situated at the boundary of information technology and diverse areas engaged with healthcare as well as medicine. It is stated that processing of healthcare data and communication are halfway associated in a virtual manner with major part of healthcare functioning and management including, patient data recording and collection, accessing literature related to medicine, assisting in communication among healthcare experts, decisionmaking in the selection of correct diagnostic methods, translating laboratory results into clinical research information.

As a general rule in healthcare, indicated in the study of Marceglia et al. (2013), there are two sub-domains of activities that emerges from healthcare, the clinical sub-area which 
assists in patient care and the subdomain of administration which is committed to the monetary and economic landscape of patient care. It is further highlighted that these sub-domains commonly share a similar information with respect to the patient, however require various perspectives that emphasize on the particular information; such as in recommending personalized medications to patients as well as treatments, the active compounds, side-effects, adverse reactions and drugdrug interactions are clinically relevant to distinguish the endorsed medication, while the expenses and repayment levels are relevant from the managerial perspective (Marceglia et al. 2013). The most significant clinical advantages of the utilization of applications such as decision support system in health informatics are constructing shared protocols based on clinical rules, practices and monitoring the adherence to them that encourages communication among various actors and roles all adding to patient's care featuring process shortcomings and recommending the relevant corrective measures, further, giving an unmistakable view on the utilization and advancement of assets, completely understanding the information stream, and distinguishing necessities and details for information framework re-engineering to advance interoperability (Mohapatra, 2013).

Burghard (2012) expresses that healthcare associations extending from single-doctor workplaces and multi-supplier groups to enormous network of medical institutions with emergency clinics and specialized hospitals and associations providing patient care stand to acknowledge noteworthy advantages by digitizing, joining as well as adequately utilizing big data. Raghupati (2014) mentioned that robust advantages of health informatics incorporate distinguishing diseases at prior stages when they can be dealt with overall effectively and successfully; examining individual on a personalized scale, health of population as well and recognizing fraud in healthcare services rapidly and proficiently.

As per O'Donoghue and Herbert (2012), Healthcare informatics utilize innovative approaches to Information technology for the optimization of data in biomedicine and healthcare such as retrieval, storage, acquisition, and application. The vital challenge in this field is constantly increasing produced information of healthcare area since this large amount of information needs data analytics with advanced pipelines to extract relevant and useful data. The study of Hassan et al. (2018) further indicates that the tools for the big data analytics extracts highly relevant data from patients' care data to offer improved services of healthcare to the patients to assist in better treatments and assistance and to create innovative tools as well as techniques to analyze and treat different diseases. The study of Yuan et al. (2016) reveals that Remote Patient Monitoring from services such as HealthCare Assistants HCA, for example are creating a huge quantity of information continuously utilizing restorative medical sensors based on Internet of Things (IoT) technology as well as environment sensors. In addition, Hassan et al. (2018) highlights that repositories based on cloud storage are employed for the storage of patient's medical information to empower their application in distinctive analytical systems to isolate the therapeutic knowledge, for example, distinguishing patients' status of health, improving techniques for the diagnosis of various diseases, and design treatment interventions. This improvement puts healthcare informatics on the apex of a novel approach of technology where these advancements are utilized to manage enormous information and get extraordinary learning and knowledge in the medicinal field. Also, every one of these advances can be used in the improvement of models that screen, monitor, and help in the curing of patients (Yuan et al. 2016).

From similar perspective of healthcare informatics, the study of Dumka and Sah (2019) proposed a design presenting a Smart Ambulance that is enabled with Information Technology and offers various facilities utilizing digital frameworks, for example, distributed cloud computing, Hadoop, Internet of Things, and Wireless Body Area Network technology. The proposed framework comprises of an ambulance furnished with WBAN sensors used to recognize continuous patient information. In addition, the WBAN sensors at that point send information to the sink node ot centre node through IoT technology by methods for the Message Queuing Telemetry Transport (MQTT) convention, also it offers aggregated IoT information which is employed in order to produce real-time aggregated data to medical specialists at remote emergency clinics. The crude information is gathered and stored in the cloud system, where different virtual machines are distributed for various systems and software to acquire and process the information. The information accumulated from various sink nodes are gathered in the cloud, where they are prepared as big data utilizing Hadoop to optimize the data in the formats of required and readable by specialists, organizations and patient. Other examples of health informatics and information technology in healthcare and medicine include Electronic health records (EHR) (Chen et al. 2012). Other than that, numerous legacy systems of various medical institutions have now moved towards computerized frameworks, such as management of patient data on cloud systems (Doukas and Maglogiannis, 2012), medical vendors are currently offering Various healthcare administrations and solutions for instance, medical imaging (Georgiou et al. 2011), electronic information trade (EDI) (Williams and Boren, 2008) and clinical decisionsupport systems (Barett et al. 2008).

\subsection{Healthcare Informatics and data analytics}

Currently, the healthcare sector produces a lot of data collected from patient-related data record-keeping, information related to health insurance, patient outcomes from clinical trials, laboratories, patient feedback, data related to health and therapeutic devices, data of drug related research, medical pictures with video, graphics and audio medical data, health strategy data (Raghupathi and Raghupathi, 2014). Ta, Liu, Nkabinde (2016), discuss that this produced data is both organized and unstructured. However, it is recommended that in the present computerized period, it is compulsory that this data is digitized. The digitization of healthcare data consequently will give improved nature of care, with diminished healthcare cost. With the data in computerized structure, healthcare associations can utilize accessible devices and innovations to dissect that data and produce important bits of knowledge in treatment (Capitalizing on the Power of Big Data for Healthcare, 2014). Yutao (2002) and Zhang \& Hu (2006) reported that in healthcare big data can be employed for 
mining, filtering, extracting of data other than offering the patients with medical analysis and ideal treatment plan. It can assist in the correct direction to change future ways of life by promoting improved healthcare. Further, the study of Baker, Lafata, Ward et al. (2001) established that analytics of big data in health care requires a huge volume of data to be gathered and recommend that the accumulation of big data must be multidimensional. In addition, it is discussed in some studies that the digitization of therapeutic data is essential to analyze from the pattern of digitization of life (Hobbs et al. 2003; Zhuo et al. 2014; Zhi et al. 2013). In 2015, a study carried out by Sathiyavathi revealed that with the digitization of health data, medical specialists can create profound insights that can streamline clinical work processes, advance care, fortify the relationship between patients and doctors, cut expenses, and improve results. However, the vast majority of the data in the sector of healthcare are not appropriate for a variety of analytical tasks.

O'Reilly (2016) sheds light on the reasons that frequently $90 \%$ of the work in a business of data Science venture particularly in healthcare is acquiring the data in a structure where it very well may be utilized in analytical tasks. To be more specific, there are two noteworthy issues associated with existing data in healthcare. Initially, countless medical records are still either transcribed or in advanced configurations that are marginally superior to manually written records, for example, scanned pictures of transcribed records or of printed reports. Therefore, acquiring medical records into a configuration that is calculable is an essential need for practically any sort of advancement in the present scenario of healthcare settings from an explanatory perspective. The study also mentions that the subsequent issue identified with the disengaged condition of the current data sources. At the end of the day, existing computerized data sources can't be joined and connected. These two issues can be settled with healthcare informatics and decision support systems from data analytics that data in a standard structure that can be shared proficiently between different electronic frameworks and that can be moved starting with one area then onto the next at the speed of the Internet.

\subsection{Decision support system in healthcare}

In general, the decisions of healthcare are relatively straightforward, including different factors, numerous choices, defective data and various inclinations of stakeholders. However, the decision-makers typically encounter issues in the systemic assessment as well as the processing of relevant information which is a process including an exchange of data between various factors. As a result, the dependability of decisionmakers on informal judgments or procedures can prompt problematic decisions in these circumstances (Baltussen and Niessen, 2006). Abbott (2014) indicates that the expansive accessibility of data has prompted ever-increasing enthusiasm for techniques for extricating valuable data and information from data and decision-making data driven. Hence, the data science domain is aimed at picking up knowledge from data and to frequently influence decisions to make them progressively reliable. In the field of Artificial Intelligence (AI), Decision Support System (DSS) is a versatile framework for handling the formalization of methods for contemplating, comprehending and problem-solving encountered by humans. The approach of problemsolving can be empowered by DSS on the basis of two principles including knowledge and the capacity to reason (Szolovits, 2019). Overall, the consideration of $\mathrm{AI}$ is based on several explanations such as an input and an operational point of view, an output and behavioral viewpoint, by evaluating its relevance, i.e., its optimal performance and by contrasting its consistency and quality with human performance (Russell and Norvig, 2018). Therefore, to model the framework under consideration, the diverse methodologies of AI result in various approaches, as an instance, for the management of complex problems, for example, considerably extensive healthcare related complexities in decision-making. In a report presented by the European Commission in 2014 for carrying out a market investigation it was recommended that mHealth market worth is likely to hike approximately about 18 billion Euro worldwide by 2017. The report also mentioned that the assessed measure of health and wellbeing related applications available is well past 100,000 . As per another report by Forbes by Elias (2015), predicted that in 2016, clients are more likely to trust in health applications more than their health specialists. Herman et al. (2015) unequivocally alluded in their paper to the utilization of tag technology, for example, barcoding scanner tags and radio-frequency identification (RFID) in smart factories so as to empower an autonomous decision making. This technology has been utilized broadly in the NHS in England and other national health administrations (Department of Health, UK, 2007; Department of Health, UK, 2010). It was also highlighted that another significant angle is the concept of distribution of intelligence and processing power into the network systems. The DSS introduced in the exploration of Abhulimen (2019) consolidated an architecture of neural network design with subsystems class of functions, the data of the components of fuzzy logic and Lyapunov stability criterion to set thresholds of disease diagnosis to determine the packing thickness of coil embolization required for cerebral aneurysm. The DSS model was connected to the treatment of aneurysm on fuzzy classifications, fuzzy conviction, and neural network algorithms on patient-specific case data. The DSS model integrated a Lyapunov stability system actualized with Levenberg-Marquardt algorithm as a training system to enhance its performance to model the diagnosis of disease based on Bayesian likelihood and fuzzy class mimicking of data with specific patient cases. The outcomes established a correlation between quantitative curl embolization packing densities that were required to lessen aneurysmal inflow. Similarly, Stivaros et al. (2010) evaluated digitalized systems of identification and detection as a substantial development regarding radiological practice similar to DSS systems.

As an instance, the diagnostic devices of Point of Care are significant devices that substantially fight against severe diseases that are infectious just as other acute as well as chronic diseases (Drain et al. 2014). Urdea et al. (2006), proposed that consolidating the test outcomes data that is created by Point of Care with patient statistical data can lead to the complete dataset which can be utilized effectively to concentrate finegrained observation data about numerous diseases utilizing data examination at individual-level just as at the level of population. In a simplified manner, it was explained that the 
datasets of demographics data joined with test outcomes can be utilized to get a singular dimension just as the level of population condition of the health of patients (Drain et al. 2014). Furthermore, by joining the above datasets with patterns of mobility data, data of location, disease pervasiveness trends, the vast healthcare data can be extracted and used for prediction tasks, which is exceedingly important for decision making in the healthcare sector.

\subsection{Data Analytics: An overview}

Yutao (2002) and Zhang \& $\mathrm{Hu}$ (2006) reported that in healthcare big data can be employed for mining, filtering, extracting of data other than offering the patients with medical analysis and ideal treatment plan. It can assist in the correct direction to change future ways of life by promoting improved healthcare.

Further, the study of Baker, Lafata, Ward et al. (2001) established that analytics of big data in health care requires a huge volume of data to be gathered and recommend that the accumulation of big data must be multidimensional. In addition, it is discussed in some studies that the digitization of therapeutic data is essential to analyze from the pattern of digitization of life (Hobbs et al. 2003; Zhuo et al. 2014; Zhi et al. 2013).

The assemblage of big data in health care is not only for the recording of the data that is identified with the therapeutic system and associated with medical procedures. The development of big data requires the accompanying four stages that begin from the approach of the Internet of Things technology as well as the internet. Subsequently the divided data are accumulated through an organized strategy, through the use of biological data and distributed or cloud computing approach, later, the relevant and beneficial data are transformed into powerful data through the Internet and approach of networking, following which successful data moves toward becoming information archive and through the approach of artificial intelligence and Internet, the repository of knowledge is transformed into product (Big data and IoT, 2014).

\subsubsection{Analytics capabilities in healthcare}

The instances of the utilization of data analytics in healthcare are Smart Pharmaceuticals, for example, smart inhalers for asthma, smart pills. The general hidden principle concept is to collect "Big Data" from a wide assortment of sensors in smart pharmaceuticals, for example, smart inhalers and insulin pens so as to prevent severe episodes of asthma and pulmonary exacerbations (Boulet et al. 2012), diminish the duration and time of sickness as well as longer hospital stays and admission and increment the personal satisfaction, in this way cutting expenses and severe conditions (Collins et al. 2015). A further developed outline of smart pharmaceuticals is observed such as several closed-loop artificial pancreases that are being created to allow progressively physiological glycemic control by fitting constant delivery of insulin dependent on consistent, remote monitoring of blood glucose levels (Trevitt et al. 2015). These artificial pancreases epitomize how smart pharmaceuticals can offer dynamic computations of dosage and doses and customize the drug delivery by monitoring fundamental signs or biomarkers. Another model is an ingestible sensor constructed by Proteus that, once in the stomach interacts with a wearable patch of the sensor. It records the time the medicine was taken and can gather extra data, including rest, body edge, and movement (Proteus, 2015). Hence, filtering and breaking down these perplexing data to determine bits of knowledge that illuminate the advancement regarding new smart healthcare products and services can demonstrate as challenging. As an example, in smart inhalers, artificial neural networks coordinate various factors over a range of peak inspiratory volumes and flows. Artificial Neural Networks have likewise offered remarkable bits of knowledge into the associations between in vitro data, attributes of patient subjects, and in vivo results (de Matas et al. 2015). There is another such current application of analytics of big data known as Google Flu Trends which is additionally being employed for health and human welfare (Carneiro and Mylonakis, 2009). Dugas et al. (2016) indicate that around the globe, a large number of clients are searching for health data on the web. Ginsberg et al. (2009) revealed that the application assesses the amount of influenza flowing in various nations worldwide utilizing the information of specific inquiry questions on its search engine as well as by complex algorithms. These data connect with the data from conventional frameworks of flu surveillance. The regular reporting of these forecasts is around one day, though conventional observation frameworks may take a long time to gather and report the data.

\section{CONCEPTUAL FRAMEWORK}

The conceptual framework based on previous findings is depicted below:

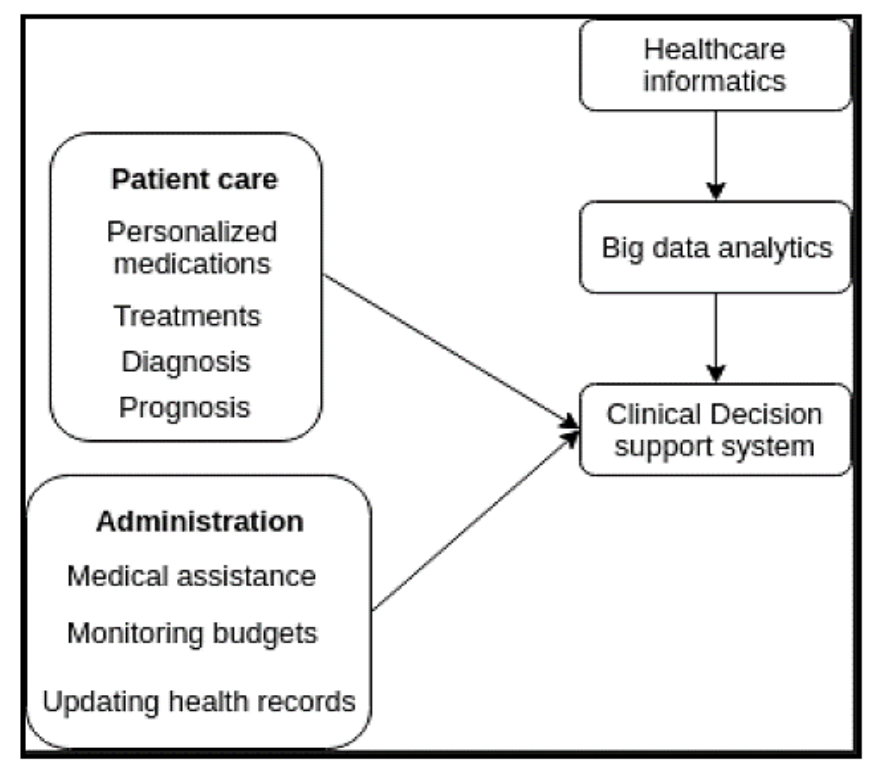

Figure 1: Conceptual Framework

\section{RESEARCH GAP}

Generally, most of the methodologies, instruments and procedures offer an alternate method to deal with the staggering measure of healthcare data and a variety of insights. However, 
healthcare data will keep on accumulating exponentially and along these lines, if healthcare frameworks don't successfully respond to the flood of unstructured data, the risk is missing the opportunity to use these data in managing their actions, decisions and resources. Further, setting up international criteria that decision-makers can consider when setting clinical needs can give clearness to stakeholders and patients on how medical councils take decisions. In addition, consortia should be organized on a global scale to assess the extent to which decision criteria will impact the funding of medical programs worldwide, which would upgrade the authenticity, straightforwardness, and responsibility of decisions and will support open trust in the clinical decision-making process. Further, it will improve the consistency of decisions, can give a chance to decision-makers to draw in the general population, and can serve the healthcare businesses about areas that require in-depth analysis and innovative systems. Nonetheless, healthcare associations need to keep up their pace with the adjustment, execution and maintaining coherence in applying the informatics tools and techniques. The state-of-the-art summary is presented below along with the research gap and future recommendations.

\begin{tabular}{|c|c|c|c|c|c|}
\hline S.No & Author & Year & Research Finding & Research Gap/Issues & Future Recommendations \\
\hline 1. & Blobel & 2013 & $\begin{array}{l}\text { System-theoretical, } \\
\text { architecture-centric approach } \\
\text { to DSS and proper strategy } \\
\text { for their representation } \\
\text { employing an Ontology } \\
\text { system is provided }\end{array}$ & $\begin{array}{l}\text { Lack of standardized } \\
\text { knowledge representation } \\
\text { systems in health DSS } \\
\text { Lack of a common } \\
\text { international language for } \\
\text { specifying clinical criteria } \\
\text { and expressions in intelligent } \\
\text { systems } \\
\text { Lack of machineprocessable } \\
\text { clinical processes and } \\
\text { observations }\end{array}$ & $\begin{array}{l}\text { Some of the examples of } \\
\text { languages and models in } \\
\text { Clinical DSS are Arden } \\
\text { Syntax, GELLO, Guidelines } \\
\text { Interchange Format (GLIF), } \\
\text { Archetype Definition } \\
\text { Language (ADL), HL7 } \\
\text { Clinical Statement Model }\end{array}$ \\
\hline 2. & Bellazzi & 2014 & $\begin{array}{l}\text { Big data provides needle in } \\
\text { the haystack approach }\end{array}$ & $\begin{array}{l}\text { Lack of good quality data and } \\
\text { reliable evaluation of results } \\
\text { The convergence of increased } \\
\text { patient involvement in } \\
\text { clinical DSS } \\
\text { Lack of big data scientists in } \\
\text { healthcare informatics } \\
\text { Managing multidimensional } \\
\text { healthcare data }\end{array}$ & $\begin{array}{l}\text { Consideration of } 4 \mathrm{Vs} \text { namely } \\
\text { Volume, Variety, Velocity, } \\
\text { and Veracity while analyzing } \\
\text { and characterizing big data } \\
\text { and designing tools and } \\
\text { techniques. }\end{array}$ \\
\hline 3. & Hu et al. & 2016 & $\begin{array}{l}\text { For outpatient doctors, } \\
\text { Simultaneously Aided } \\
\text { Diagnosis Model (SADM) } \\
\text { (90\% accuracy) was } \\
\text { implemented to assist } \\
\text { diagnosis. }\end{array}$ & $\begin{array}{l}\text { Due to the high number of } \\
\text { outpatients, outpatient } \\
\text { doctors have a high } \\
\text { diagnostic time and } \\
\text { increased congestion in } \\
\text { operating times of hospital }\end{array}$ & $\begin{array}{l}\text { To present an improved } \\
\text { SADM Model focusing on } \\
\text { the large dataset of unlabeled } \\
\text { medical } \\
\text { images for minimizing } \\
\text { diagnostic time with DSS }\end{array}$ \\
\hline 4. & Wang et al. & 2016 & $\begin{array}{l}\text { The study proposed five } \\
\text { strategies for healthcare } \\
\text { organizations to apply and } \\
\text { implement initiatives of their } \\
\text { big data analytics }\end{array}$ & $\begin{array}{l}\text { IT adoption of the healthcare } \\
\text { strategies is slow } \\
\text { A large amount of } \\
\text { unstructured clinical data and }\end{array}$ & $\begin{array}{l}\text { Analytical personnel should } \\
\text { be given specific } \\
\text { consideration in the } \\
\text { framework of big data } \\
\text { analytics to leverage as a }\end{array}$ \\
\hline
\end{tabular}


International Journal of Engineering Research and Technology. ISSN 0974-3154, Volume 13, Number 1 (2020), pp. 107-116

(C) International Research Publication House. https://dx.doi.org/10.37624/IJERT/13.1.2020.107-116

\begin{tabular}{|c|c|c|c|c|c|}
\hline S.No & Author & Year & Research Finding & Research Gap/Issues & Future Recommendations \\
\hline & & & & $\begin{array}{l}\text { lack of an established } \\
\text { relationship between } \\
\text { variables. }\end{array}$ & $\begin{array}{l}\text { means to increase healthcare } \\
\text { business value. }\end{array}$ \\
\hline 5. & Sulley et al. & 2018 & $\begin{array}{l}63 \% \text { of industry } \\
\text { professionals have seen the } \\
\text { impact of DSS on population } \\
\text { health and } 60 \% \text { believe it } \\
\text { has one way or another } \\
\text { impacted preventive care }\end{array}$ & $\begin{array}{l}\text { Lack of the input of } \\
\text { physician or healthcare } \\
\text { provider in clinical DSS } \\
\text { Lack of public awareness for } \\
\text { health informatics by } \\
\text { healthcare organizations }\end{array}$ & $\begin{array}{l}\text { There should be an } \\
\text { investment at the level of } \\
\text { education in biomedical } \\
\text { informatics to enhance and } \\
\text { optimize the components of } \\
\text { healthcare delivery. }\end{array}$ \\
\hline 6. & $\begin{array}{l}\text { Islam, } \\
\text { Hasan, } \\
\text { Wang }\end{array}$ & 2018 & $\begin{array}{l}\text { Out of } 117 \text { reviewed studies, } \\
48 \% \text { conducted descriptive } \\
\text { analysis } 43 \% \text { conducted } \\
\text { Predictive analytics, and only } \\
9 \% \text { of studies conducted } \\
\text { prescriptive analytics. }\end{array}$ & $\begin{array}{l}\text { Lack of prescriptive analytics } \\
\text { in practice and integration of } \\
\text { clinical DSS } \\
\text { Most of the studies focus on } \\
\text { clinical and administrative } \\
\text { decisionmaking }\end{array}$ & $\begin{array}{l}\text { To integrate approaches } \\
\text { based on domain-expert } \\
\text { knowledge, to reduce the } \\
\text { error of prediction, and } \\
\text { consolidation of models that } \\
\text { are predictive in genuine } \\
\text { healthcare work } \\
\text { environments. }\end{array}$ \\
\hline 7. & $\begin{array}{l}\text { Hassan et } \\
\text { al. }\end{array}$ & 2019 & $\begin{array}{l}\text { In Remote patient monitoring } \\
\text { models of Ambient Assisted } \\
\text { Living (AAL), Naïve Bayer } \\
\text { and J48 displayed good } \\
\text { efficiency with the datasets } \\
\text { with Spark for distribution, } \\
\text { processing and storage of the } \\
\text { different clusters }\end{array}$ & $\begin{array}{l}\text { Lack of parallel systems that } \\
\text { are fault-tolerant to analyze } \\
\text { exponentially increasing data }\end{array}$ & $\begin{array}{l}\text { The Smart Remote patient } \\
\text { monitoring models built } \\
\text { based on cloud-based } \\
\text { systems will greatly assist } \\
\text { and save the lives of elderly } \\
\text { patients }\end{array}$ \\
\hline
\end{tabular}

\section{FINDINGS AND DISCUSSION}

The findings of the study indicate that the diagnosis and treatment of patients as well as other medical services assisted by computer-based technologies supported by artificial intelligence such as decision support system, pattern recognition, artificial neural networks and image analysis as a rule, is a developing domain of future healthcare, which has discovered its application in the treatment of diverse diseases and treatment interventions. The results indicate that there are two types of medical services in which clinical DSS can be applied that are patient care which includes personalized treatment regimes, diagnosis, prognosis, outpatient remote monitoring, and administrative services that include monitoring funding, health records and staff related services that will participate in the clinical DSS. Both of the areas of healthcare industry can equivalently benefit with the application of DSS. Further, in the healthcare sector, the multidimensional as well as protected and secured data, along with an easily readable format and data analytics in health informatics are required to help data-driven decision-making which is the key strategy for management and monitoring of diseases and alleviation of diseases if there should be an occurrence of diseases outbreaks. Moreover, with the accessibility of healthcare technologies and relevant and beneficial data, the general decision-making procedures which already depended on the conjectures, previous experience or on models from the real world that were restricted, are now can be constructed depending on the quality healthcare data and their subsequent products and services with the help of decision support systems. In addition, as there is an increasing acquisition of healthcare data by the healthcare organizations associations that are constantly fragmenting, classifying and analyzing it, it is leading towards a characteristic revolution in healthcare informatics to scientifically strengthen and enhance devices, decisions, predictions, approximations, techniques and tools with proficiency and efficiency. Further, it is highlighted that Decision Support System fills in as a computational and smart technique and a tool to help clinicians to access the large medical records, clinical data and methods associated with the diagnosis and treatment of diseases. In addition, Decision Support System offers a secondary assessment to the clinician for target diagnosis to manage and design treatment choices that could be accessible to the patient (Abhulimen, 2019). As per the early research of Lederberg (1987), numerous modelers fabricated complex lumped models of the cardiovascular system incorporating the blood dissemination system as well as the related controls of the neuronal endocrine system. Further, DSS has advanced recently to help the health specialists and researchers to design pre-and post-operative treatment choices to understand and settle on the precise decision in the examination of the huge amount of clinical data associated with 
current medical diagnosis and viable healthcare management and planning (Alavi et al. 1992). In general, the majority of the methodologies, instruments and procedures offer an alternate method to deal with the staggering measure of healthcare data and give workable data. By examining the current innovative framework and determining the tools, current researchers are developing, healthcare organizations can identify what kind of data investigation system will perform best for them. In addition, the ongoing investigation additionally offers extraordinary conceivable outcomes for medical practices and healthcare associations, particularly in inpatient settings, the status of a patient can change immediately with DSS. Also, constant investigation furnishes doctors with ceaselessly refreshed data that considered increasingly successful and convenient for patient care management and proactive treatment strategies.

\section{CONCLUSION}

In healthcare, for the acknowledgement of the challenges associated with DSS and analytics of data, forefront big data advancements which can oversee and dissect the gigantic quantity of data in clusters on the basis of the previous investigation on recorded data, as well as real-time, are needed. The discussed techniques and tools in healthcare data analytics and health informatics need an infrastructure as well as design with reliability, characterized scalability, execution and adaptation to critical tolerance to failure attributes. The usage of decision support systems utilizing big data innovations provides the framework for healthcare analytics to conduct large-scale management and examination of data from different sources. Such a concept frames the reason for the entrance and adequacy of healthcare administrations and, accordingly, the productivity of data analytics and informatics approaches in the zone of healthcare decision-making as well. Hence, the healthcare data will keep on increasing exponentially and in the case that healthcare systems don't effectively react to the surge of unstructured data, they hazard letting off the chance to utilize these data in dealing with their activities. The utilization of big data, ongoing investigation, and prescient modeling will revolutionize the healthcare field by expanding those opportunities past responding to rising issues.

\section{REFERENCES}

[1] Abhulimen, K. E., 2019. Modeling Decision Support System for Optimal Disease Diagnosis and Treatment of Cerebral Aneurysm. Journal of Engineering and Science in Medical Diagnostics and Therapy 2(2), 021002.

[2] Akyildiz, I., \& Rudin, H., 2001. Pervasive computing. Computer Networks-The International Journal of Computer and Telecommunications Networking, 35(4), 371.

[3] Alavi, M., and Joachimsthaler, E. A., 1992. Revisiting DSS Implementation Research: A Meta-Analysis of the Literature and Suggestions for Researchers. MIS Q. 16(1), 95-116.
[4] Almadani, B., Bin-Yahya, M., Shakshuki, E.M., 2015. E-AMBULANCE: Real-Time Integration Platform for Heterogeneous Medical Telemetry System. Procedia Computer Science 63, 400-407. 5. Baker, A.M., Lafata, J.E., Ward, R.E., et al. 2001. A Web-Based diabetes care management support system. Joint Comm. J. Qual. Improv., 27(4), 179-190

[5] Baltussen, R., Niessen, L.W., 2006. Priority setting of health interventions: the need for multicriteria decision analysis. SSRN Electronic Journal.

[6] Barnett, M.L., Landon, B.E., O'malley, A.J., Keating, N.L. and Christakis, N.A., 2011. Mapping physician networks with self- reported and administrative data. Health services research, 46(5), pp.1592-1609.

[7] Barrett, J.S., Mondick, J.T., Narayan, M., Vijayakumar, K. and Vijayakumar, S., 2008. Integration of modeling and simulation into hospital-based decision support systems guiding pediatric pharmacotherapy. BMC medical informatics and decision making, 8(1), p.6.

[8] Bellazzi, R. (2014). Big Data and Biomedical Informatics: A Challenging Opportunity. IMIA Yearbook, 9(1), 8-13. doi:10.15265/iy-20140024

[9] Blobel, B. (2013). Knowledge representation and management enabling intelligent interoperability principles and standards. Stud. Health Technol Inform. $186,3-21$.

[10] Big Data and Internet of Things: A Roadmap for Smart Environments, 2014. Studies in Computational Intelligence.

[11] Boulet, L.P., Vervloet, D., Magar, Y., Foster, J.M., 2012. Adherence: the goal to control asthma. Clin Chest Med 33(3), 405-417

[12] Brodnik, M., Layman, E., Watzlaf, V., 2012. Health Informatics Research Methods: Principles and Practice, Perspect Health Inf Manag. American Health Information Management Association, PMC3329204

[13] Budinger, T.F., 2003. Biomonitoring with Wireless Communications. Annual Review of Biomedical Engineering 5, 383-412.

[14] Burghard, C., 2012. Big data and analytics key to accountable care success. IDC health insights, pp.1-9.

[15] Capitalizing on the Power of Big Data for Healthcare, 2014, SAS Global Forum Washington.

[16] Carneiro, H.A. and Mylonakis, E., 2009. Google trends: a web-based tool for real-time surveillance of disease outbreaks. Clinical infectious diseases, 49(10), 15571564.

[17] Chen, Y.-Y., Lu, J.-C., Jan, J.-K., 2012. A Secure EHR System Based on Hybrid Clouds. Journal of Medical Systems 36, 3375-3384.

[18] Collins, F.S., Varmus, H., 2015. A New Initiative on Precision Medicine. New England Journal of Medicine 372, 793-795. 
[19] Cortada, J., Gordon, D., Lenihan, B., 2012. The Value of Analytics in Healthcare, Report No.: GBE03476USEN-00, IBM Institute for Business Value: Armonk, NY, USA, Center for Medicare and Medicaid Services.

[20] Department of Health, UK., 2007. Coding for success: Simple technology for safer patient care.

[21] Department of Health, UK., 2010. Review of coding for success.

[22] Diaby, V., Campbell, K., Goeree R., 2013. Application of multicriteria decision analysis in healthcare: a systematic review and bibliometric analysis. Oper Res Health Care, 2(1-2), 20-24.

[23] Doukas, C., Maglogiannis, I., 2012. Bringing IoT and Cloud Computing towards Pervasive

[24] Healthcare. 2012 Sixth International Conference on Innovative Mobile and Internet Services in Ubiquitous Computing.

[25] Drain, P.K., Hyle, E.P., Noubary, F., Freedberg, K.A., Wilson, D., Bishai, W.R., Rodriguez, W., Bassett, I.V., 2014. Diagnostic point-of-care tests in resource-limited settings. Lancet Infect. Dis. 14(3), 239-249.

[26] Dugas, A.F., Jalalpour, M., Gel, Y., Levin, S., Torcaso, F., Igusa, T. and Rothman, R.E., 2013. Influenza forecasting with Google flu trends. PloS one, 8(2), p.e56176.

[27] Dumka, A., \& Sah, A. (2019). Smart ambulance system using concept of big data and internet of things. Healthcare Data Analytics and Management, 155176.doi:10.1016/b978-0-12-815368-0.00006-3

[28] Elias, J., 2015. In 2016, users will trust health apps more than their doctors.

[29] European Commission, 2014. Digital Single Market, mHealth, Infographics.

[30] Ganslandt, T., Prokosch, H.U., 2009. Perspectives for Medical Informatics. Methods of Information in Medicine 48, 38-44.

[31] Georgiou, A., Prgomet, M., Markewycz, A., Adams, E. and Westbrook, J.I., 2011. The impact of computerized provider order entry systems on medical-imaging services: a systematic review. Journal of the American Medical Informatics Association, 18(3), pp.335-340.

[32] Ginsberg, J., Mohebbi, M.H., Patel, R.S., et al. 2009. Detecting influenza epidemics using search engine query data. Nature 457(7232), 1012-1014.

[33] Godoe, H., 2000. Innovation regimes, R\&D and radical innovations in telecommunications. Research Policy 29, 1033-1046.

[34] Grayson, A., Shawgo, R., Johnson, A., Flynn, N., Li, Y., Cima, M., Langer, R., 2004. A BioMEMS Review: MEMS Technology for Physiologically Integrated Devices. Proceedings of the IEEE 92, 6-21.

[35] Hackbarth, A.D., and Berwick, D.M., 2012. Eliminating
Waste in US Health Care. J. Am. Med. Assoc. 307, 1513-1516.

[36] Hassan, M.K., Desouky, A.I.E., Elghamrawy, S.M., Sarhan, A.M., 2018. Big Data Challenges and Opportunities in Healthcare Informatics and Smart Hospitals. Security in Smart Cities:

[37] Models, Applications, and Challenges Lecture Notes in Intelligent Transportation and

[38] Infrastructure 3-26.

[39] Hatcher, M., Heetebry, I., 2004. Information Technology in the Future of Health Care. Journal of Medical Systems 28, 673-688.

[40] Herland, M., Khoshgoftaar, T.M., Wald, R., 2014. A review of data mining using big data in health informatics. Journal Of Big Data 1, 2.

[41] Hobbs, G., Bauer, J.C., Keillor, A.R., 2003. New perspectives on the quality of care: reducing medical errors through cultural change and clinical transformation. Medscape Money Med, 4(2).

[42] Hu, Y., Duan, K., Zhang, Y., Hossain, M. S., Rahman, S. M., \& Alelaiwi, A. (2016, 07). Simultaneously aided diagnosis model for outpatient departments via healthcare big data analytics. Multimedia Tools and Applications, 77(3), 3729-3743.

[43] Islam, M., Hasan, M., Wang, X., Germack, H., \& NoorE-Alam, M. (2018, 05). A Systematic Review on Healthcare Analytics: Application and Theoretical Perspective of Data Mining. Healthcare, 6(2), 54.

[44] Krumholz, H.M., 2014. Big Data And New Knowledge In Medicine: The Thinking, Training, and Tools Needed For A Learning Health System. Health Affairs 33, 1163 1170 .

[45] Lederberg, J., 1987. How Dendral Was Conceived and Born. ACM Conference on History Medical Informatics, Bethesda, MD, 5-19.

[46] Marsh, K., Lanitis, T., Neasham, D., Orfanos, P., Caro, J., 2014. Assessing the value of healthcare interventions using multi-criteria decision analysis: a review of the literature. Pharmaco-Economics, 32, 345-365.

[47] Matas, M.D., Shao, Q., Biddiscombe, M.F., Meah, S., Chrystyn, H., Usmani, O.S., 2010. Predicting the clinical effect of a short acting bronchodilator in individual patients using artificial neural networks. European Journal of Pharmaceutical Sciences 41, 707-715.

[48] National Health Expenditure Projections (NHEP), 2018. Accuracy analysis of the short-term (10year) national health expenditure projections, Centers for Medicare \& Medicaid Services, Office of the Actuary.

[49] Olla, P. (2005). Evolution of GSM Network Technology. Encyclopedia of Multimedia Technology and Networking, 290-294.

[50] O’Donoghue, J., Herbert, J., 2012. Data Management 
within mHealth Environments. Journal of Data and Information Quality 4, 1-20.

[51] O’Reilly, T., Steele, J., Loukides, M., Hill, C. 2012. How Data Science Is Transforming Health Care Solving the Wanamaker Dilemma, 1-29.

[52] Proteus. 2015. U.S. FDA accepts first digital medicine new drug application for Otsuka and Proteus Digital Health.

[53] Raghupathi, W., Raghupathi, V., 2014. Big data analytics in healthcare: promise and potential. Health Information Science and Systems 2.

[54] Rota, P., Groeneveld-Krentz, S., Reiter, M., 2015. On automated flow cytometric analysis for MRD estimation of acute lymphoblastic leukaemia: a comparison among different approaches. In: IEEE international conference on Bioinformatics and Biomedicine (BIBM). IEEE, 438-441.

[55] Russell, S.J., Norvig, P., 2018. Artificial intelligence: a modern approach. Pearson Education Inc.

[56] Sathiyavathi, R., 2015. A Survey: Big Data Analytics on Healthcare System, Contemporary Engineering Sciences 8(3), 121 - 125.

[57] Stivaros, S. M., Gledson, A., Nenadic, G., Zeng, X. J., Kearne, J., and Jackson, A., 2010, Decision Support Systems for Clinical Radiological Practice-Towards the Next Generation, Br. J. Radiol. 83(995), 904-914.

[58] Sulley, S. (2018). Impact of Clinical Decision Support Systems (CDSS) on Health Outcomes Improvement. Int J Health Sci Res. 8(5), 292-298.

[59] Szolovits, P., 2019. Artificial Intelligence and Medicine. Chapter 1 in Szolovits, P. (Ed.) Artificial Intelligence in Medicine. Boulder, Colorado: Westview Press, 1-19.

[60] Ta, V.-D., Liu, C.-M., Nkabinde, G.W., 2016. Big data stream computing in healthcare real-time analytics. 2016 IEEE International Conference on Cloud Computing and Big Data Analysis (ICCCBDA).

[61] Trevitt, S., Simpson, S., Wood, A., 2015. Artificial Pancreas Device Systems for the Closed-Loop Control of Type 1 Diabetes. Journal of Diabetes Science and Technology 10, 714-723.

[62] Urdea, M., Penny, L.A., Olmsted, S.S., Giovanni, M.Y., Kaspar, P., Shepherd, A., Wilson, P., Dahl, C.A., Buchsbaum, S., Moeller, G., Hay Burgess, D.C., 2006. Requirements for high impact diagnostics in the developing world. Nature, 73-79.

[63] Wang, Y., Kung, L., \& Byrd, T. A. (2016). Big data analytics: Understanding its capabilities and potential benefits for healthcare organizations. Technological Forecasting and Social Change, 126, 3-13.

[64] Williams, F. and Boren, S., 2008. The role of the electronic medical record (EMR) in care delivery development in developing countries: a systematic review. Journal of Innovation in Health Informatics,
16(2), pp.139-145.

[65] Yang, J., Li, J., Mulder, J., Wang, Y., Chen, S., Wu, H., Wang, Q., Pan, H., 2015. Emerging information technologies for enhanced healthcare. Comput. Ind., 69, 3-11.

[66] Yuan, X., Elhoseny, M., El-Minir, H.K., Riad, A.M., 2016. A Genetic Algorithm-Based, Dynamic Clustering Method Towards Improved WSN Longevity. Journal of Network and Systems Management 25, 21-46.

[67] Yutao, L., 2002. Current situation and progress of medical information education. Med Inform, 15(03), pp 163-165.

[68] Zhang, S.J., Hu, S.Q., 2006. Status quo of medical information education in China's higher education institution: an investigation. Chin J Med Libr Inform Sci., 15(06), pp 51-54.

[69] Zhi, Y.J., Zhang, H., Xie, Y.M. et al. 2013. Clinical outcomes of parenterally administered Shuxuetong: analysis of hospital information system data. China J Chin Med, 38(18), 3116-3120

[70] Zhuo, Z., Zhai, W., Cai, D., et al. 2014. Research on integrated application of tumor: magnetic induction hyperthermia treatment planning system and modern. Med Inform Syst, 31(1), 187-191 